\title{
ГИПОТЕЗА ОБ УСТРОЙСТВЕ СОЛНЕЧНОЙ СИСТЕМЫ
}

\section{Моргалюк Виктор Дмитриевич}

инженер

Аннотация: В статье приведены некоторые условия, выполнение которых позволяет рассматривать Солнечную систему как частично обособленную, а движение планет по своим орбитам устойчивым. Выводы основаны на обобщении понятия «интерференция» на волновые процессы вообще.

Ключевые слова: Гравитация, стоячая волна в волноводе, орбиты планет.

(Определения, используемые в статье, даны для жидкостей или газов).

Стоячая волна в волноводе (далее - СВ) - физическое явление, при котором когерентные бегущие волны давления в волноводе образуют неподвижную волну давления с чередованием амплитуд давления (узлов и пучностей) - интерференция волн давления. При возникновении СВ в волноводе происходит преобразование кинетической энергии источников колебаний (бегущей волны давления) в потенциальную энергию фиксированного перепада давлений по длине волновода. Образуются зоны с повышенным и с пониженным давлением. Небольшие частицы (примеси) находятся в сечениях с минимальным давлением, причем это положение устойчиво, т.к. любое отклонение частиц вдоль оси волновода переводит их в зону с более высоким давлением и вынуждает вернуться в прежнее положение.

Предположим, что данное выше определение, в общем виде, справедливо и для других видов энергии, в частности для волн гравитации, поскольку любая энергия определяется своей несущей частотой колебаний. Следует заметить, что при образовании стоячей волны в волноводе, сечения с низким (или высоким) давлением располагаются вдоль волновода через расстояния равные или кратные длине когерентных бегущих волн, которые и образуют стоячую волну. В случае с волнами гравитации - устойчивое положение материальных частиц (или планет) будет в сечениях с высоким уровнем гравитации, при этом, необходимым условием является наличие 
волновода внутри которого происходит образование стоячих волн гравитации, следствием которых будет наличие устойчивых и неподвижных относительно волновода плоскостей с повышенными и пониженными уровнями гравитации. $\mathrm{B}$ плоскостях $\mathrm{c}$ высокой гравитацией могут располагаться скопления планет. По аналогии со спектром видимого света для волн гравитации также должен быть свой спектр волн гравитации, а значит при образовании «стоячей волны» в определенном месте нужно рассматривать фиксированную частоту «бегущей волны» гравитации.

На рис. 1 позиция 2 изображено положение плоскости Солнечной системы и другой Системы, аналогичной Солнечной Рис. 1 позиция 3.

С учетом сказанного выше, можно предположить, что для поиска аналогичных Земле планет нужно двигаться вдоль границ Солнечной системы (вдоль волновода) перпендикулярно плоскости орбит планет Солнечной системы, т.е. к Системе рис.1 поз. 3. Между этими Системами располагается зона (зоны) с пониженной гравитацией и, возможно, что она (они) менее интенсивна, чем аналогичная зона за внешней границей Солнечной системы рис. 1 позиция 1 .

Для планет Солнечной системы в качестве «своего» волновода, возможно, следует рассматривать плоскую зону 2 в которой находятся орбиты планет и которая ограничивается внешним гравитационным волноводом 1 рис. 1.

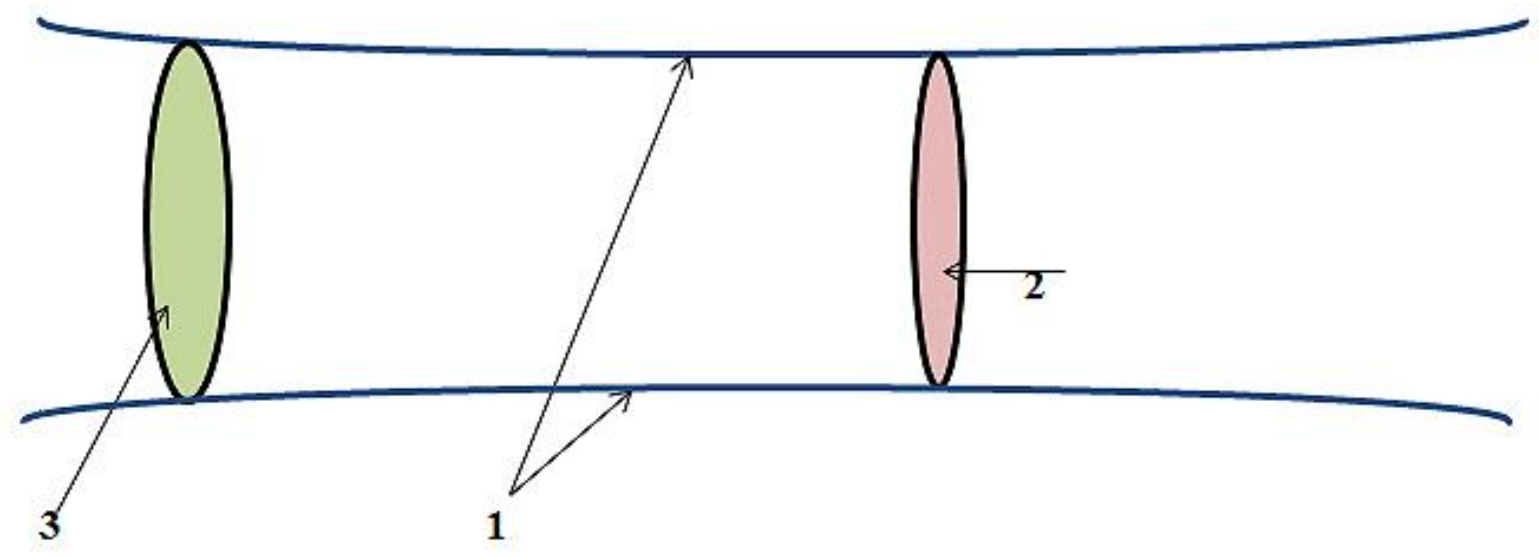

Рис. 1. 
1. Гравитационный волновод, определяющий внешние границы Солнечной системы.

2. Плоскость орбит планет Солнечной системы - высокий уровень гравитационного поля - внутренний волновод.

3. Плоскость орбит планет Системы, подобной Солнечной - высокий уровень гравитации.

Теперь, с этой точки зрения, рассмотрим устройство Солнечной системы Рис 2. Гравитационные волны, идущие от Солнца, могут отражаться от пояса астероидов (внутренний волновод Земной группы) и образовывать стоячие волны гравитации для планет «земной» группы. При этом расстояния между орбитами планет должны быть одинаковы, что и выполняется в действительности. Эти расстояния примерно равны 50 млн. км. Если учесть, что присутствуют и гравитационные волны, которые образуют плоскость Солнечной системы и эти волны перпендикулярны гравитационным волнам Солнца, которые образуют орбиты планет, то результатом сложения этих волн будет некоторое кольцеобразное поле с высокой гравитацией (кольцеобразный тоннель), в пределах которого и находится орбита Земли. Другие планеты «земной» группы вращаются внутри своих «кольцеобразных тоннелей». Орбиты, при этом, будут устойчивы. Для других планет Солнечной системы (Юпитер - Нептун) внешним волноводом может являться граница Солнечной системы в районе Пояса Койпера (Рис 2) и, наверное, другая используемая частота волн гравитации от Солнца, т.к. расстояния между планетами внешней группы равны или кратны 750 млн. км.

Конечно, остается вопрос - что и как образует гравитационный волновод?

Предложенная точка зрения не претендует на аксиому, но, поскольку объясняет причину устойчивости движения планет по орбитам, - может иметь право на жизнь.

Возможно, что и Постоянная тонкой структуры может быть применима при вычислении размеров орбит планет - «кольцеобразных туннелей».

Рассматривать движение планет по орбитам только с точки зрения равновесия сил гравитации и центробежных нелогично, т.к. такое равновесие неустойчиво.

Выводы: 


\section{ФУНДАМЕНТАЛЬНАЯ ПРИКЛАДНАЯ НАУКА: СОСТОЯНИЕ \\ И ТЕНДЕНЦИИ РАЗВИТИЯ}

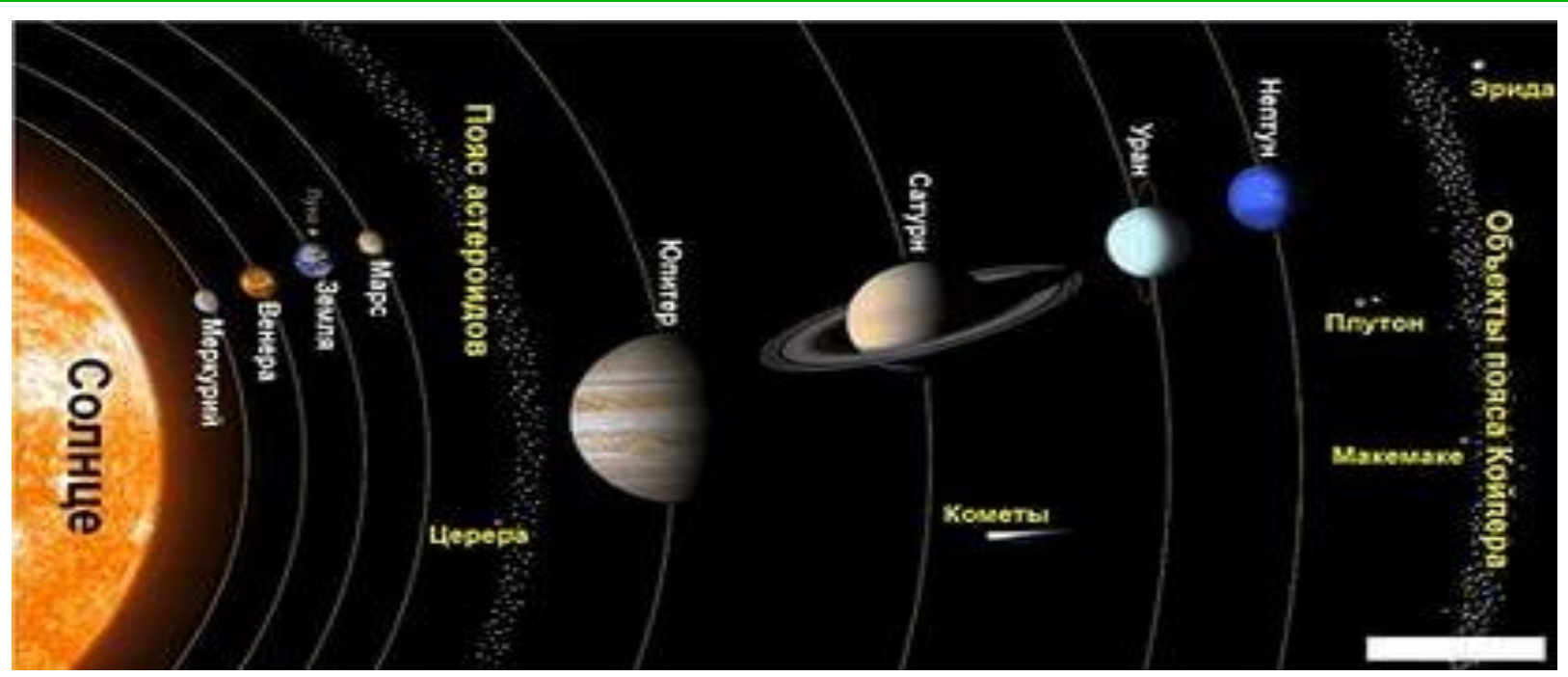

Рис. 2.

Поскольку на сегодня нет научной теории явления «Стоячая волна в волноводе» - однозначных выводов сделать нельзя, но, если проводить аналогию со стоячими волнами давления для жидкостей или газов, которые преобразуют кинетическую энергию бегущих волн в потенциальную энергию, то в случае бегущих волн гравитации образуются повышенные и пониженные уровни гравитации в соответствующих местах в плоскости планет Солнечной системы. Низкие уровни располагаются между орбитами планет, а поскольку планеты обладают магнитным полем и вращаются, то логично предположить, что есть присутствие магнитного и (или) электромагнитного поля между орбитами планет и максимум этого поля может находиться в плоскости, наклоненной к плоскости орбит планет Солнечной системы, что приводит к наклонам осей вращения планет относительно плоскости орбит. Можно рассуждать и далее, но далее без научной теории не разобраться.

(C) В.Д. Моргалюк, 2021 